\title{
Comprehensive Landscape Ecology Stability Assessment of a Coal Gangue Backfill Reclamation Area
}

\author{
Liu Xuan ${ }^{1 *}$, Liu Wenkai², Zhang Hebing ${ }^{1}$, Niu Haipeng ${ }^{1}$ \\ ${ }^{1}$ School of Surveying and Land Information Engineering, Henan Polytechnic University, \\ Jiaozuo 454000, Henan, China \\ ${ }^{2}$ School of Civil Engineering, Henan Institute of Engineering, \\ Zhengzhou 451191, Henan, China
}

Received: 30 April 2015

Accepted: 23 February 2016

\begin{abstract}
The landscape of a coal gangue backfilling reclamation region in the Yang Quan First mine has experienced remarkable land backfilling reclamation over the past few decades. Effective management strategies are needed to protect the environment in these areas as well as the sustainable development of land resources. In this paper, a study of pattern change is proposed by using five landscape metrics and a stability analysis of features derived from land cover maps in order to investigate their magnitude and its comprehensive ecological stability in the gangue backfilling reclamation region between a separate time period (2000-14). The results illustrate that:

- The artificial reclamation project disturbed the landscape so that patching and ecological stability has changed.

- The vegetation landscape patch indices all decreased during the study period, showing that the reclamation had a greater impact on the vegetation.

- The comprehensive index of ecological effects of landscape ecology was 0.3615 , showing that the area's landscape remained stable during the study period.

- Backfill landscape stability is lowest, which indicates that landscape stability is mainly affected by human disturbance, while the influence of natural and semi natural landscapes is relatively low.
\end{abstract}

Keywords: land use, coal gangue backfilling reclamation land, GIS, landscape index, landscape ecology, landscape comprehensive stability

\section{Introduction}

Coal gangue is a hazardous industrial waste that is produced while mining coal. Dumping this waste in coneshaped heaps is a common disposal method that not only

*e-mail: keystonelx@126.com occupies a great deal of land resource, but also causes a considerable threat to the surrounding environment, for instance through surface subsidence, impoundment, and soil pollution [1]. As an alternative solution, foundation backfilled with coal gangue can make the best use of a large amount of coal gangue, consequently reducing environmental pollution [2]. Furthermore, backfill engineering would help mining areas dispose of coal 
gangue in order to improve the ecological environment and enhance land use [3, 4].

Currently for coal gangue backfill reclamation in China, the main methods are highly concentrated on agricultural land or construction [5]. Its negative effects become increasingly prominent and instead we have been focusing on ecological restoration and landscape construction [6]. Under the traditional ecological viewpoint, the stability of a state can be evaluated by three different stability properties: constancy, persistence, and resilience [7]. In recent decades, a large amount of ecological research has focused on the characterization and modeling of temporal and spatial patterns of land mosaics with a landscape perspective [8-9]. Landscape ecology deals with landscape pattern, function, and dynamics [10, 11]. We will use several methods and tools that have been developed in recent decades to detect landscape dynamics and function and to explore the interaction between landscape pattern and ecological advances $[12,13]$. These methods, such as landscape metrics and Markov chain models, are mainly used to characterize and monitor the dynamics of landscape patterns [14]. a)

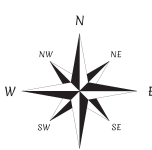

The People's Republic of China

d)

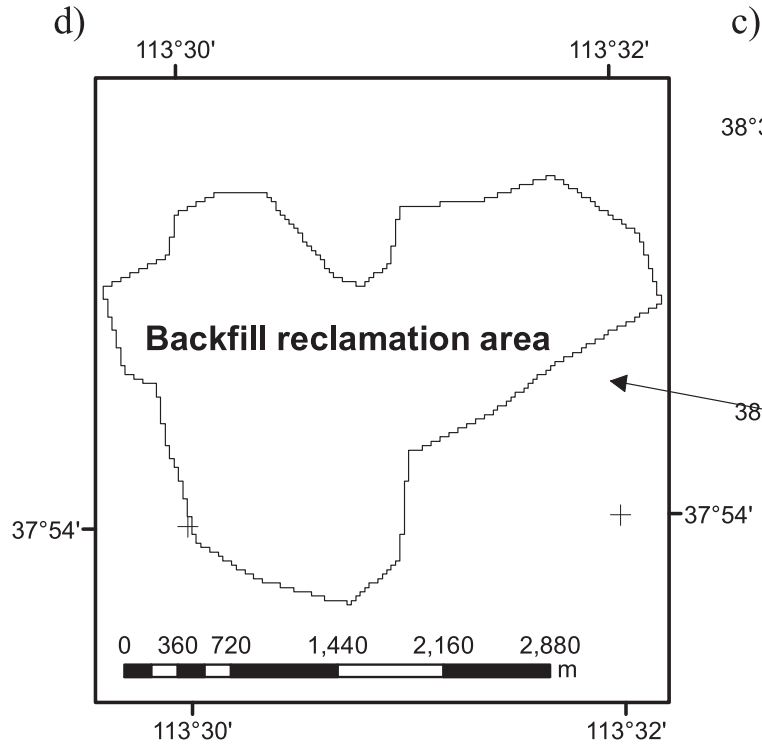

c) b)

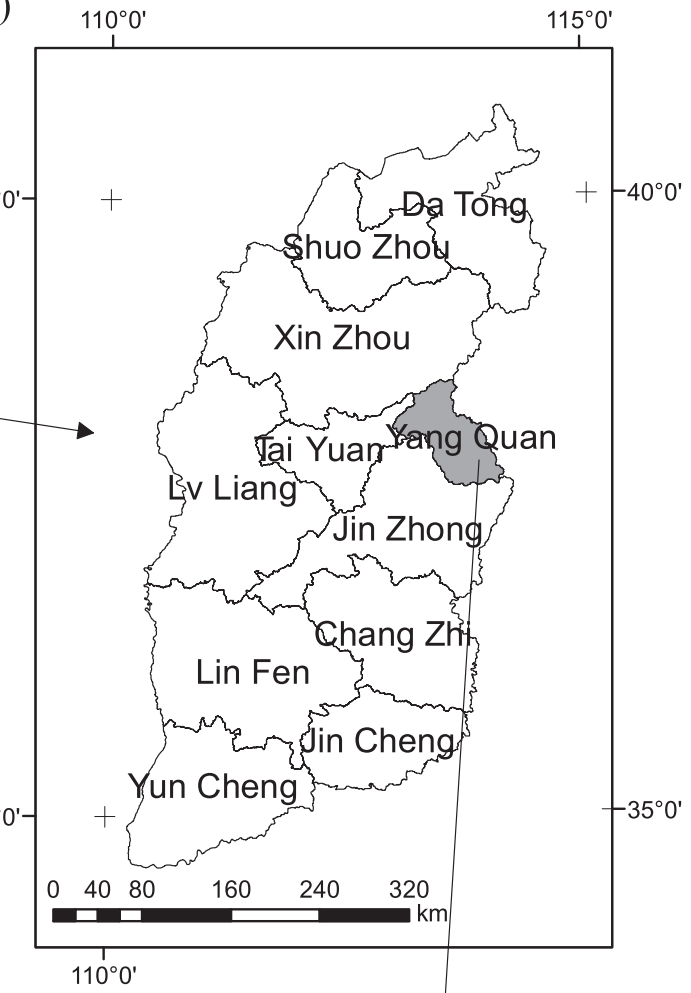

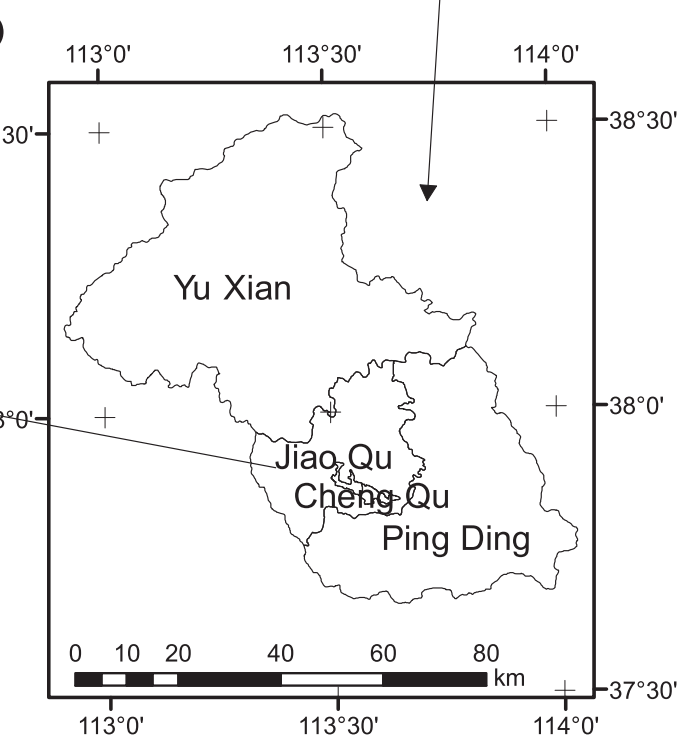

Fig. 1. Location of the study area a) map of China, b) map of Shan Xi Province, c) map of Yang Quan, and d) map of backfill reclamation area. 
Coal gangue backfill reclamation is a process that completely reshapes landforms using artificial engineering. It layers the coal gangue and covered soil in a low-lying area that's been drained and dredged [15]. Landforms will give rise to transformation after backfill engineering is finished. Landform transformation, accordingly, will lead to landscape change, which is manifested as land cover transformation [16, 17]. For coal gangue filling reclaimed lands, it would be important to understand the magnitude and pattern of land-cover change. Furthermore, landscape stability is a proven index that is effective for revealing past changes [18].

This paper takes advantage of stability analysis of features derived from landscape pattern analysis using GIS procedures and RS images TM8 and OLI8 from 2000 and 2014 integrated with landscape metrics analysis in order to show pattern dynamics and prove the approach to an eventual stable state after land reclamation.

\section{Materials and Methods}

\section{Study Area}

The study area (Fig. 1) was in the city of Yang Quan in Shan Xi Province. Over the past 50 years, the accumulation of the reclamation area was nearly $40 \mathrm{hm}^{2}$. The total backfill reclamation area is about $33.07 \mathrm{hm}^{2}$ and is southwest of the Yang Quan First mine.

\section{Image Data Processing}

Thematic Mapper (TM) satellite images acquired in 2000 at a resolution of $30 \mathrm{~m}$ and Operational Land Imager (OLI) in 2014 at a resolution of $15 \mathrm{~m}$, were used in this study. The remote sensing processing software used was ENVI 5.1 and GIS was IDIRISI 18.0 TerrSet. Land use and cover types were classified into gangue, backfill, built-up, and vegetation. Researchers randomly collected 100 samples as training data, which were used in the maximum likelihood classification to perform the classification. For each sample the land cover patches were accurately delineated to obtain maximum precision in the classification. The final file was converted into a raster having the same resolution and extension of land cover maps. Classification result of land use cover patches in 2000 and 2014 is shown in Fig. 2. Overall accuracy exceeded $90 \%$ in the two period's image classification, which fully met the analysis requirements.

\section{Methods}

\section{Landscape Metrics Investigated}

Essentially, landscape variables are shown in the number, size, area, and shape of a patch's basic property. Detection of landscape variables between different periods were performed through cross matrices with the crosstab tool of GIS software IDRISI 18, and Fragstats 3.3 was also used for landscape pattern metrics analysis. In this study, five landscape metrics were used [19]:

- The number of patches per class (NP), which is a simple measurement of the extent of subdivision or fragmentation of each class into patches.

- Area weighted mean shape index (AWMSI), which is a shape-based metric that measures the complexity of patch shape weighted by patch size.

- Area weighted mean patch size (AWMPS), which is a measure of mean patch size with a lower weight given to the small patches in the landscape.

- Largest patch index (LPI), which quantifies at the class level the percentage of total landscape area comprised by the largest patch.

- Mean proximity index (MPI), which estimates the isolation of patches for a certain class within a given search radius that was set as $100 \mathrm{~m}$ in this study .

\section{Landscape Ecological Stability Analysis}

Landscape stability assessment measures the risk of a certain area after a disturbance and analyzes the relationship between disturbance and stability and other relationships between the structure of ecological areas and stability

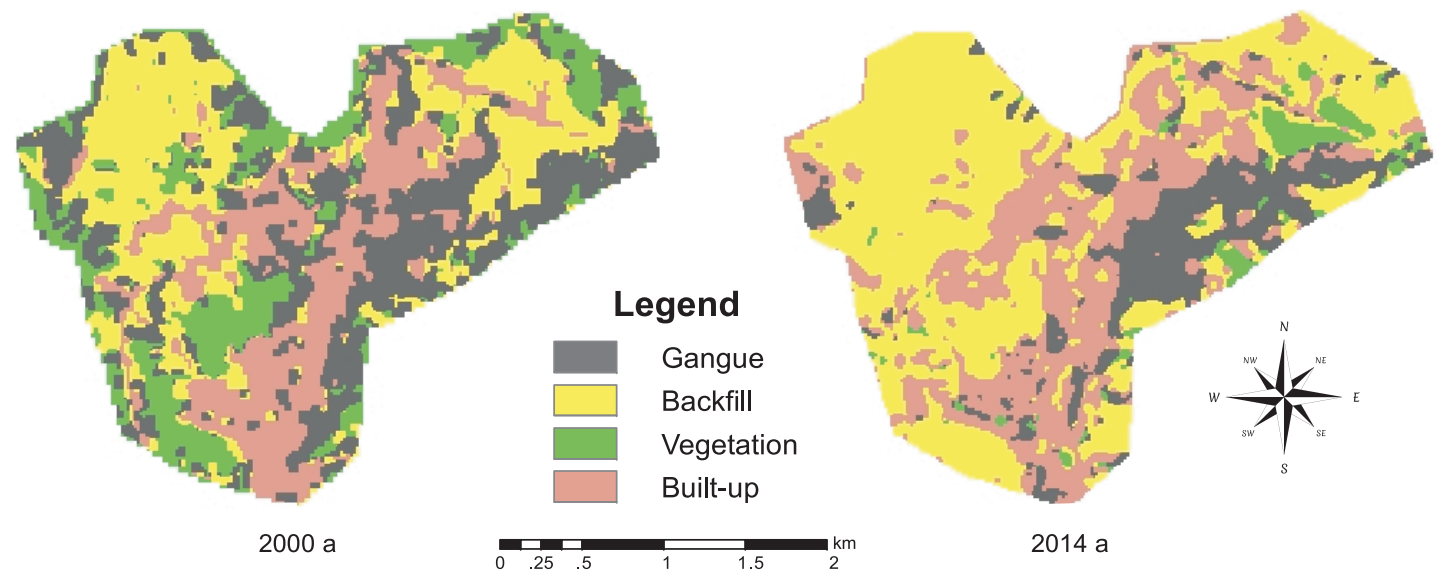

Fig. 2. Land use patches classification in 2000 and 2014. 
[20]. For regional landscape ecological safety, there is a close correspondence between ecological structure and disturbance intensity. Patch is the basic composition unit of the landscape pattern. In addition, it is the main object of landscape ecological change [21]. Therefore, this paper combines with different periods of remote sensing image patch changes to calculate disturbance propagation conditions and ecological effects on the stability index of the study area (depending on disturbance intensity).

Disturbance is a process in which landscape structure, function, and dynamics occur. Disturbance factor not only includes a variety of local natural factors, but also is an artificial factor for a small range of human activities [22]. Therefore, the landscape will generate disturbance patches and land use cover change is displayed in the remote sensing images after the disturbance.

The disturbance propagation condition index reflect the status of regional ecological safety quantified by the degree of disturbance influence. The set area consists of roughly the same area by $n$ patches that can analyze randomly. The patch properties were divided into instability patch combination $\mathrm{C} 1$ (consist of $\mathrm{d}$ instability patches) and stable C2 (consisting of n-d stable patches). The proportion of instability patch combination $\mathrm{C} 1$ was $p$ :

$$
p=d / n
$$

Disturbance propagation conditions index $R$ is:

$$
R=1-(1-p) / m
$$

...where $m$ is disturbance capability correspondence with the instability patch and range is $[1,9]$.

Regional landscape ecological stability index $P$ :

$$
P=\left|1 /\left(1-e^{-0.89845 / m}\right)\right|
$$

A comparison was made between disturbance propagation conditions index and regional landscape ecological stability index. The regional ecology remains stable when the former index is lower than that of the regional ecological disturbance. On the contrary, when the disturbance propagation conditions index is higher than the regional ecological disturbance, the regional ecological becomes instable.

Regional ecology was provided with a high degree of spatial heterogeneity and manifested as interactive to patch. Regional ecological safety not only depended on the various types of patch, but also is controlled by the regional ecological structure [23], which includes: instability patch area ratio, dispersion coefficient, and uniformity and shape coefficient [24]. The regional ecological structure index was calculated respectively through the following formula:

1. Instability patch area ratio $D$

The co-efficiency can be described by the percentage of instable patch to the ecological region's total area. Regional ecology, which is related to the instability patch area, will become unstable, if the portion of instability patch area increases. The term instability patch area ratio in Eq. (4) can be expressed as follows:

$$
D=S_{0} / S
$$

...where $D$ is the instability patch area ratio, $S_{0}$ is the total area of instability patch, and $S$ is the total area.

2. Instability patch dispersion $N$

This coefficient represents the distribution of the instability patch in the area. Dispersion coefficient is low, which reflects instability patch separated from each other and disturbance spread scarcely, thus the regional ecology keeps stability and vice versa. The coefficient $N$ in Eq. (5) can be presented by:

$$
N=1-\frac{2 S \sum d_{i}}{S_{0} \pi T}
$$

...where $d_{i}$ is the minimum distance between patch, $S_{0}$ is the total area of instability patch, $S$ is the total area, and $T$ is the number of instability patch.

3. Instability patch uniformity $Q$

Instability patch uniformity represents the patch area degree of uniformity. In general, the more uniform the distribution of the instability patch, the smaller the influence on the stability of regional ecology. The coefficient can be written in the following form:

$$
Q=\frac{1}{S_{\max }} \sqrt{\frac{\sum\left(S_{i}-\bar{S}\right)^{2}}{T}}
$$

...where $S_{\max }$ is the area of largest instability patch, $S_{i}$ is the area of instability patch $I, S$ is the average area of instability patch, and $T$ is the number of instability patch.

4. Instability patch uniformity shape coefficient $Z$

Shape co-efficiency refers to the degree of instability patch contact with the substrate. The higher degree of instability patch contact with the substrate, the less stable the ecological region. It usually is represented by the average ratio of instability patch perimeter to equal the circles perimeter. On account of this the ratio is usually between $1 \sim 8$. It was divided by eight to ensure that it is less than or equal to one so as to conveniently be compared with other coefficients. A greater value is explained by the instability patch having sufficient contact with the substrate. Calculations were performed using the following equation:

$$
Z=\frac{1}{8 T} \sum \frac{P_{i}}{2 \sqrt{\pi S_{i}}}
$$

... where $P_{i}$ is side-length of the instability patch $i, S_{i}$ is the area of instability patch $i$, and $T$ is the number of instability patch. 
Table 1. Quantification change of various land use cover types of the study area in 2000 and 2014.

\begin{tabular}{|c|c|c|c|c|c|c|}
\hline \multirow{2}{*}{ The land category } & \multicolumn{2}{|c|}{2000} & \multicolumn{2}{c|}{2014} & \multicolumn{2}{c|}{ Quantification change } \\
\cline { 2 - 7 } & Area $\left(\mathrm{hm}^{2}\right)$ & Patch & Area $\left(\mathrm{hm}^{2}\right)$ & Patch & Area $\left(\mathrm{hm}^{2}\right)$ & Patch \\
\hline Gangue & 11.23 & 117 & 7.79 & 31 & -3.44 & -60 \\
\hline Backfill & 8.77 & 113 & 14.07 & 28 & 5.3 & 93 \\
\hline Built-up & 6.96 & 111 & 8.66 & 24 & 1.7 & 19 \\
\hline Vegetation & 7.13 & 51 & 3.57 & 18 & -3.56 & -52 \\
\hline Total & 34.09 & 392 & 34.09 & 101 & - & - \\
\hline
\end{tabular}

5. Comprehensive index of ecological effects $H$

A comprehensive index of ecological effects is obtained by added the four coefficients that have given weights as follows:

$$
H=w_{1} D+w_{2} N+w_{3} Q+w_{4} Z
$$

... where $w_{1}, w_{2}, w_{3}$, and $w_{4}$ are weights of instability patch area ratio, dispersion, uniformity, and shape coefficient, respectively.

The comprehensive index of the ecological effects index reflects the degree of interaction of various effect factors [25]. This index ranges from 0 to 1 . A value closer to 1 illustrates that the regional landscape ecology has changed significantly and the degree of ecosystem stability is low. A value closer to 0 illustrates that regional landscape ecology has changed insignificantly so that the ecosystem is stable.

\section{Results}

\section{General Characteristics of Land Cover Change}

Landscape stability includes the stability of landscape feature spatial patterns. Function was determined by pattern. Consequently, this would be an analyzed feature of landscape spatial pattern on the basis of comprehensive stability of the regional landscape [26].

To ensure the land use cover classification data in consonance with spatial data of 2000 and 2014, classification data was vectorized in IDRISI. Land use cover change was obtained with spatial analysis, which overlaid land use cover access data in 2000 and 2014 (Table 1).

Table 1 shows the quantification change of various land use cover types. For land use cover area change, the coal gangue and vegetation were reduced by $3.44 \mathrm{hm}^{2}$ and $3.56 \mathrm{hm}^{2}$, while backfill and built-up areas were increased by $5.3 \mathrm{hm}^{2}$ and $1.7 \mathrm{hm}^{2}$. Correspondingly, for land use cover patch change, coal gangue and vegetation were reduced by 60 and 52, while backfill and built-up were increased by 93 and 19 .

Fig. 3 displays the changes of various types of land use spatial distribution. Coal gangue as the main landscape type in the study area was significantly decreased during the study period. The vegetation patch both increased and decreased, but increased the condition significantly more than decreased. This conversion indicated that backfill reclamation destroyed area vegetation; furthermore, vegetation patches increased as a result of the shelterforest that was planted. Backfill and construction patches increased significantly and the backfill patch increase area was in accordance with the vegetation patch decrease area. It is noted that the mining area was still backfilling the coal gangue as a result of the backfill reclamation area increasing considerably. Meanwhile, the mining area carried out construction on the land that emerged from transporting the coal gangue to backfill reclamation and demolished construction that was no longer suitable for use. As a result, increased patches of built-up areas were close to the decrease patches. As previously mentioned, the regional landscape was disturbed, giving rise to landscape patch type and the ecological stability that changed.

Landscape stability change is a combined effect that generates both natural processes and human activities. The general characteristics analysis of regional land use spatial change combined with the changing trend of different types of land use for reciprocal transformation that was helpful to understand the process and reason for landscape change. The transition probability matrix that can better reflect the possibility of different land use patch reciprocal transformation is a commonly used method for analysis of land use patch dynamics [27]. It clearly shows a decrease in change rate (negative values) over almost all transitions (small exceptions are in bold characters) and an increased stability in each land cover class along the diagonal (positive values). Transition probability of four landscape patch types in the study area was obtained by dynamic monitoring and analysis in the entire time period with MARKOV analysis module in IDRISI (Table 2).

Table 2 shows transition probability. It can be easily observed that backfill was characterized by the highest transition probability of $80.59 \%$, followed by built-up (79.79\%), vegetation (7.88\%), and gangue (0.01\%). Conversely, vegetation was mainly changed into backfill (71.15\%). Throughout the entire study period, vegetation and coal gangue conversion frequency were higher than the two landscape patch types converted to other land type patches. The transition probability matrix analysis was consistent with the general characteristics of land cover change. 


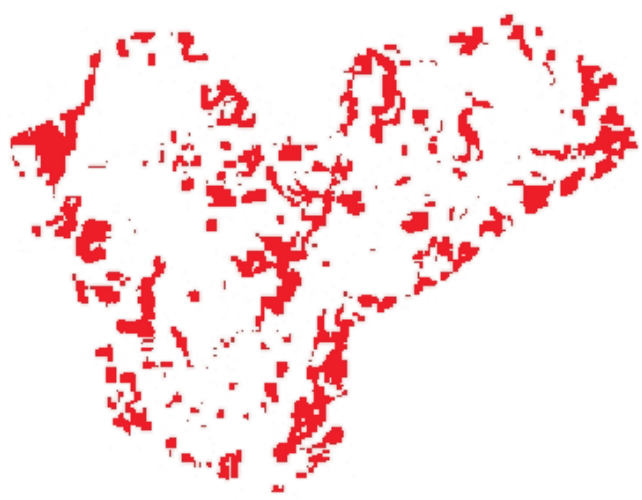

Gangue

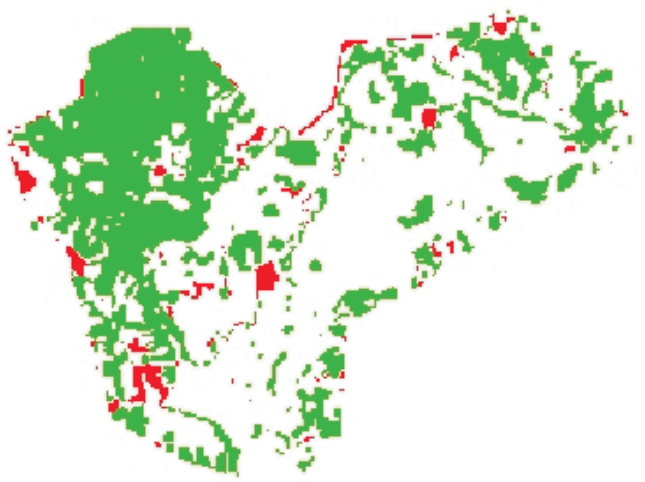

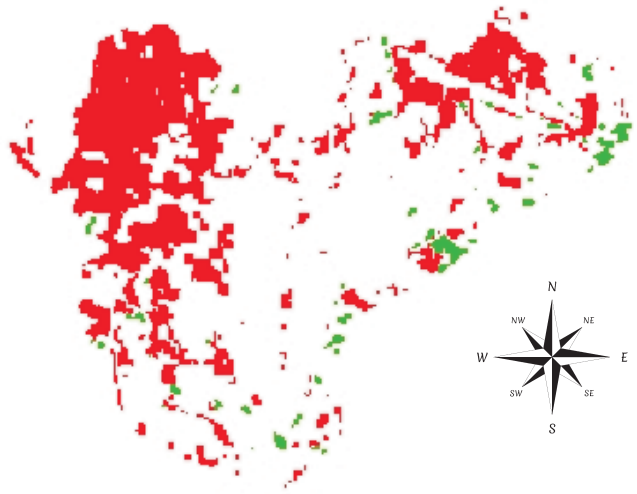

Backfill

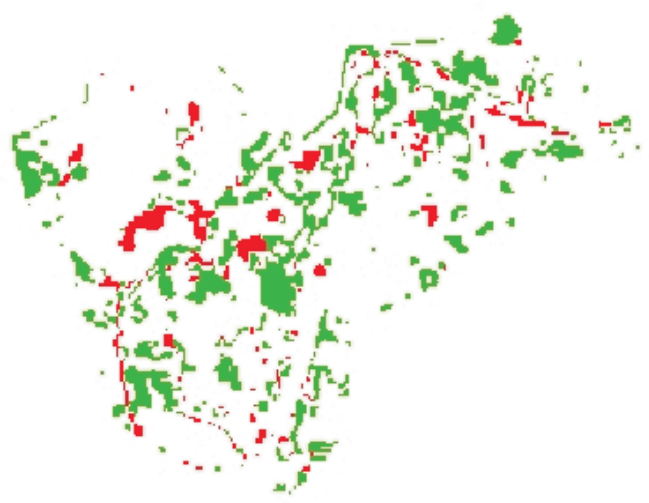

Built-up

Vegetation

Legend

Unchanged Decrease Increase

\begin{tabular}{llllll}
\hline & & & & & \\
m
\end{tabular}

Fig. 3. Land use patches classification in 2000 and 2014.

\section{Landscape Patch Change Metrics Analysis}

Landscape patch change metrics of the study area in the entire study period was calculated by Frastats. The landscape metrics changes are presented in Fig. 4. Gangue and vegetation area decreased and backfill and vegetation area increased within the study period (Fig. 4a). Reducing the number of patches for all of the landscape patch types demonstrated space fragmentation was reduced and landscape distribution tends to concentrate, which was attributed to the area of each landscape type increase

Table 2. Transition probability matrix of landscape patches in 2000 and 2014.

\begin{tabular}{|c|c|c|c|c|}
\hline & Gangue & Vegetation & Backfill & Built-up \\
\hline Gangue & 0.01 & 8.18 & 61.07 & 30.74 \\
\hline Vegetation & 0.00 & 7.88 & 71.15 & 20.97 \\
\hline Backfill & 0.00 & 0.77 & 80.59 & 18.64 \\
\hline Built-up & 0.00 & 0.69 & 19.52 & 79.79 \\
\hline
\end{tabular}

(Fig. 4b). AWMSI and AWMPS are metrics that measure the complexity of patch shape weighted by the patch area [28]. In terms of AWMSI and AWMPS, gangue, backfill, and built-up patch increased, whereas vegetation decreased over the study period. As stated above, the shown complexity of gangue, backfill, and built-up patch declined. More sporadic patches emerged within the vegetation patch, which is reduced after disturbances that may result in vegetation patches that are more and more complex and irregular (Fig. 4c, Fig. 4d). The largest patch index was in order to characterize the landscape dominance.

LPI approaches 0 when the largest patch of the corresponding patch type is increasingly small, while LPI is equal to 100 when the entire landscape consists of a single patch. As seen from Fig. 4e, gangue, backfill, and built-up had a considerable increase from 2000 to 2014, and on the contrary vegetation decreased, suggesting the effect of backfill reclamation, which leads to vegetation landscape dominance decreasing and fragmentation increasing significantly. The MPI of gangue and backfill increased, whereas vegetation and built-up decreased (Fig. 4f). Patch dispersion and landscape fragmentation 

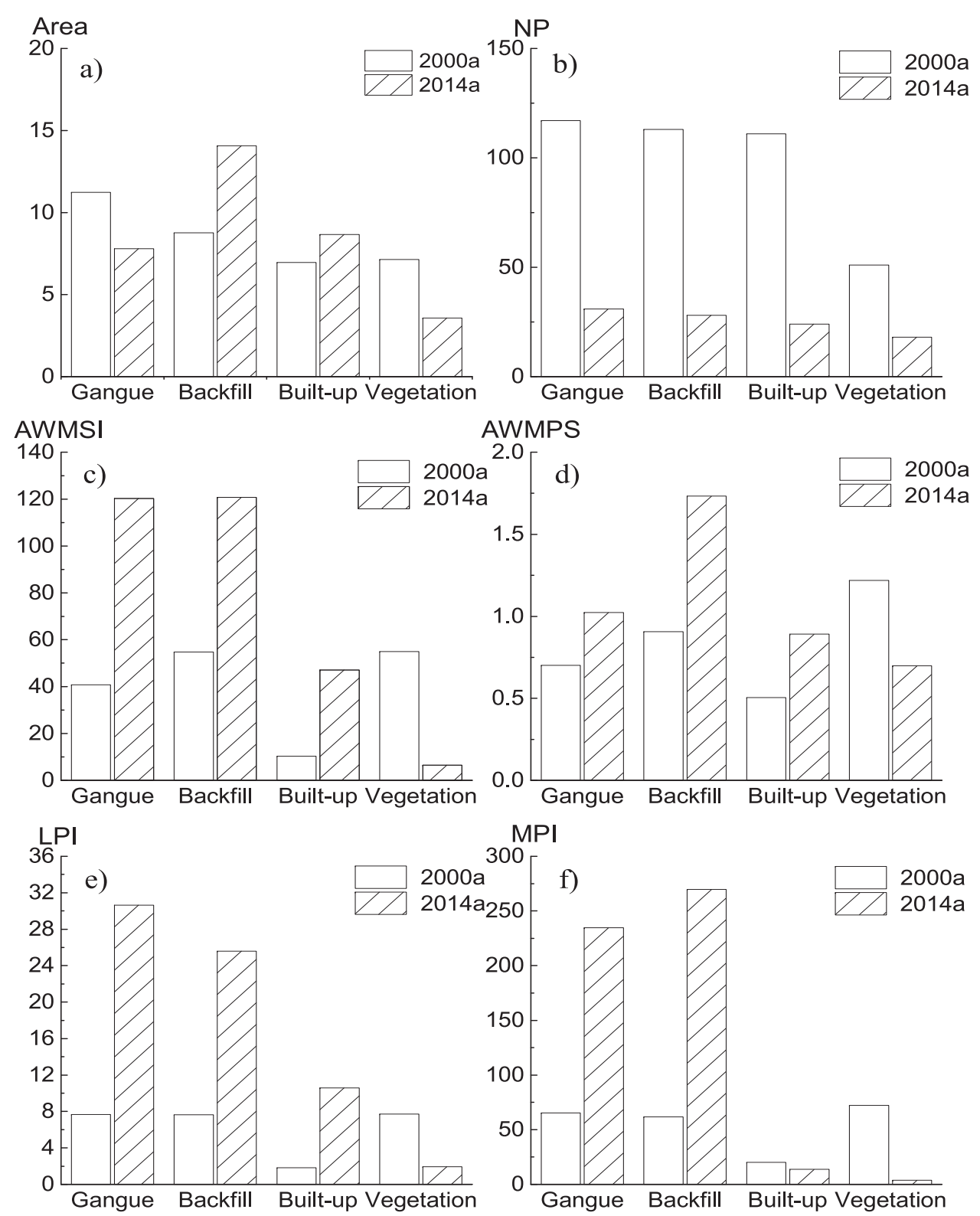

Fig. 4. Metrics of landscape change in 2000 and 2014.

of gangue and backfill declined closer promoted patches. Built-up MPI decreased due to temporary mining builds due to construction on the land that emerged by transporting the coal gangue to backfill reclamation in order to augment landscape fragmentation.

\section{Landscape Ecological Stability Analysis}

Landscape ecological stability index was calculated based on methods described previously (Table 3 ).

Backfill and vegetation landscape ecological stability

Table 3. Results of landscape ecological structure coefficient.

\begin{tabular}{|c|c|c|c|c|}
\hline The land category & Unstable patch area ratio & $\begin{array}{c}\text { Interference } \\
\text { capability }\end{array}$ & $\begin{array}{c}\text { Disturbance propagation } \\
\text { condition index }\end{array}$ & $\begin{array}{c}\text { Ecological stability } \\
\text { index }\end{array}$ \\
\hline Gangue & $48.78 \%$ & 4 & $12.81 \%$ & $8.26 \%$ \\
\hline Backfill & $84.55 \%$ & 8 & $1.93 \%$ & $4.13 \%$ \\
\hline Built-up & $57.58 \%$ & 5 & $8.48 \%$ & $6.61 \%$ \\
\hline Vegetation & $73.24 \%$ & 7 & $3.82 \%$ & $4.72 \%$ \\
\hline Regional landscape & $66.47 \%$ & 6 & $5.59 \%$ & $5.51 \%$ \\
\hline
\end{tabular}


Table 4. Result of ecological impact comprehensive index.

\begin{tabular}{|c|c|c|c|c|}
\hline Affecting coefficient & Area ratio & Dispersion coefficient & Uniformity & Shape coefficient \\
\hline Value & 0.5673 & 0.0878 & 0.2516 & 0.1089 \\
\hline Weight & 0.5122 & 0.1106 & 0.1432 & 0.2310 \\
\hline Index of ecological impact & 0.3615 & & & \\
\hline
\end{tabular}

index were greater than the disturbance propagation condition index of $1.79 \%$ and $3.82 \%$. Anti-disturbance capability and quality of landscape ecology decreased, while simultaneously the landscape pattern tended to be unstable. With the backfill reclamation area enlarging, vegetation and environmental balance was affected, which gave arise to the quality of the ecological environment degradation. On the contrary, the gangue, built-up, and total regional landscape ecological stability indices were less than the disturbance propagation condition index. These landscapes keep stability within the study period.

\section{Regional Landscape Ecological Impact Analysis}

We quantitatively analyzed the degree of landscape ecology change in order to determine the weight of each coefficient. The weights of the ecological impact comprehensive index were determined by the sequence synthesis method and based on ecological impact coefficient score. The result of the comprehensive index of ecological effects is shown in Table 4.

The value of ecological impact comprehensive index was 0.3615 , indicating that the regional landscape ecology remains stable in the study period.

\section{Discussion and Conclusion}

Many intermediate stages were included during the process of coal mining and reclamation so that the landscape in the reclamation area was in dynamic change. Different reclamation modes and land use landscapes that were formed by different reclamation periods led to the landscape metrics being diverse from each other. Consequently, regional landscape stability was different [29]. In line with previous studies, ecologists regard it as the definition of stability that the capability of the landscape ecology system to resist disturbances and the capability of the landscape ecology system to recover after disturbances [30, 31]. The capability of the coal mining reclamation area landscape ecology system to resist disturbances manifested the extent of landscape patches changed after reclamation engineering disturbance [32].

In our work we proposed a framework to investigate landscape stability in terms of land cover patches. From the obtained results (Table 1), it can be easily deduced that a strong simplification of landscape pattern for the backfilling reclamation area occurred in the considered period of time. From different types of landscape transformation viewpoints, indeed, the main feature is the backfilling patch increasing while the vegetation patch decreases [33]. Area and patch of the backfilling reclamation area changed significantly, meaning that the reflected landscape was disturbed by backfilling reclamation engineering and landscape patch and ecological stability changed. But because of the structure of the backfilling reclamation area landscape ecology system which was directly related to the local climate, the environment, soil texture, and other factors were very complex, while this paper did not consider coal mining in the soil and water pollution. To a certain extent, this would affect the accuracy of the evaluation.

The total number of patch number of all land use cover types declined in the study period and the entire mining landscape fragmentation was reduced (Fig. 4). The landscape pattern showed continuous, balanced peer technology and trends to the high connectivity change. It can be noted that the trend of development for the landscape pattern is continuous, equilibrium equivalence, high connectivity [34]. Each metric of gangue, backfill, and build-up is beneficial to regional landscape stability. As far as gangue and backfill patch were concerned, all the metrics except the total number of patches decreased significantly during the study period, which depicted landscape dominance of the two patches, which were significant, and instead of reducing dispersion and fragmentation of the patch, proximity increased. In terms of built-up patch, in addition to MPI others metrics all increased as well as the entire vegetation patch metrics decreasing. Coal gangue backfilling reclamation engineering played a positive role in processing coal gangue, reducing stockpiles, and promoting land use efficiency. However, it damaged vegetation to a certain extent, which was its disadvantage in improving the ecological environment in the mining area.

Ecological impact comprehensive index was 0.3615 (Table 4), indicating that the regional landscape ecology remains stable in the study period. Analysis of regional ecological comprehensive stability from the landscape transformation perspective after disturbance, backfill, gangue, and vegetation patches changed most significantly. While from the view of the ecological stability index, backfill soil is lowest; conversely gangue is highest, illustrating that ecological stability of the landscape in backfill reclamation was mainly disturbed by artificial backfill engineering, but the impact of natural and seminatural was less.

In general, we argue that because of limited resources and the difficulty of maintaining an optimal reference state for the gangue backfill reclamation area landscapes, one 
of the major challenges could be to identify management opportunities that maximize ecological functions as well as the landscape services while minimizing restrictions on human land use and costs. In other words, an effective and reliable management strategy for gangue backfill reclamation area landscapes should provide for a dynamic equilibrium between land use, restoration/conservation costs, environmental protection, and landscape capacity to provide goods and services. This equilibrium should be maintained over time through adaptive management, taking into account the spatial and temporal scale of natural processes as well as the shifting between human and ecological perspectives of the landscape. The development of a standardized analysis of landscape equilibrium is still to be realized due to data scarcity and spatial and time-variability of the processes driving the landscape evolution.

\section{Acknowledgements}

This work was supported by grants from the National Natural Science Foundation of China (Nos. 41371524, 41301617, 41401610, and U1404402).

\section{References}

1. QI X.X., WANG X.J., LI Y., GUO X.X., WANG J.F. Study on properties of the coal gangues from Xinjiang main coal mine regions and their utilization suggestions. Journal of China Coal Society. 35, 1197, 2010 [In Chinese].

2. XIE H.L., WANG P., HUANG H.S. Ecological Risk Assessment of Land Use Change in the Poyang Lake EcoEconomic Zone, China. Int. J. Environ. Res. Public Health. 10, 328, 2013.

3. LI S.Z., BAI G.L., TIAN Y.B. Study on Environmental Effect of Foundation Backfilled with Coal Gangue. Journal of Earth Sciences and Environment. 33, 412, 2011 [In Chinese].

4. HUANG Y., WANG Y.J., WANG M., TIAN F., AO J.F. Effect of mining subsidence on soil erosion in mountainous area of the Loess Plateau. Transactions of the Chinese Society of Agricultural Engineering. 30, 228, 2014 [in Chinese].

5. WANG P.J., HU Z.Q., SHAO F., JIANG Z.D., QIAO Z.Y., LIU D.W., CHEN Y.K. Feasibility analysis of Yellow River sediment used as the filling reclamation material of mining subsidence land. Journal of China Coal Society. 39, 1133, 2014 [In Chinese].

6. SCHERR S.J., BUCK L., WILLEMEN L., MILDE J.C. Ecoagriculture: Integrated Landscape Management for People, Food, and Nature. Encyclopedia of Agriculture and Food Systems. 41, 1, 2014.

7. YANG H.B., LI Y.F., CHEN J.W., GUO H.L. Comprehensive evaluation on landscape ecology of Kashi River basin. Journal of Arid Land Resources and Environment. 28, 67, 2014 [In Chinese].

8. ANTROP M. Landscape change and the urbanization process in Europe. Landscape Urban Plan. 67, 9, 2004.

9. GERI F., AMICI V., ROCCHINI D. Human activity impact on the heterogeneity of a Mediterranean landscape. Applied Geography. 30, 370, 2010

10. FORMAN R.T.T., GODRON M. Landscape ecology. 1986, New York: Wiley.
11. ALVARO R., ESPERANZA A.T., EUTIQUIO G., JOSE M.F., ANA I.G. A simplified model to assess landscape quality from rural roads in Spain. Agriculture, Ecosystems \& Environment. 142 (3), 205, 2011.

12. RUSSELL G.C. A review of assessing the accuracy of classifications of remotely sensed data. Remote Sensing of Environment. 37, 35, 1991.

13. RENETZEDER C., SCHINDLER S., PETERSEIL J., PRINZ M.A., MUCHE R.S., WRBKA. T. Can we measure ecological sustainability landscape pattern as an indicator for naturalness and land use intensity at regional, national and European level. Ecological Indicators. 10 (1), 39, 2010.

14. LI B.L. Stability analysis of a nonhomogeneous Markov landscape model. Ecological Modelling. 82, 247, 1995.

15. ZHANG L.P., ZHANG S.W., YE H.C., HUANG Y.F. Landscape Indices of Land Damage and Land Reclamation in an Opencast Coal Mine. Resources Science. 36 (1), 55, 2014 [In Chinese].

16. PAUKERT C.P., PITTS K.L., WHITTIER J.B., OLDEN J.D. Development and assessment of a landscape-scale ecological threat index for the Lower Colorado River Basin. Ecological Indicators. 11 (2), 304, 2011.

17. BENEDEK Z., NAGY A., RACZ I.A., JORDAN F., VARGA Z. Landscape metrics as indicators: Quantifying habitat network changes of a bush-cricket Pholidoptera Transylvania in Hungary. Ecological Indicators. 11 (3), 930, 2011.

18. MA C.A., WANG Q.R. Ecological Evaluation Model for Large Opencast Mine and Its Application. Journal of Mining \& Safety Engineering. 23 (4), 446, 2006 [In Chinese].

19. PELOROSSO R., CHIESA S.D., TAPPEINER U., LEONE A., ROCCHINI D. Stability analysis for defining management strategies in abandoned mountain landscapes of the Mediterranean basin. Landscape and Urban Planning. 103, 335, 2011.

20. TURNER M.G., ROMME W.H., GARDNER R.H., O'NEILL, TIMOTHY K.K. A revised concept of landscape equilibrium: Disturbance and stability on scaled landscapes. Landscape Ecology. 8 (3), 213, 1993.

21. TONGWAY D.J., HINDLEY N. Landscape Function Analysis: Procedures for Monitoring and Assessing Landscapes with Special Reference to Mine sites and Rangelands CSIRO. Sustainable Ecosystems. 14, 2004.

22. BRAZNER J.C., DANZ N.P., TREBITZ A.S., NIEMI G.J., REGAL R.R., HOLLENHORST T. Responsiveness of Great Lakes wetland indicators to human disturbances at multiple spatial scales: A multi-assemblage assessment. Journal of Great Lakes Research. 33 (S3), 42, 2007.

23. ZHANG S.Q., ZHANG B., WANG A.H. Relationship between changes of wetland area and regional climates in Sanjiang Plain. Adv. Earth Sci. 16 (6), 83, 2001.

24. XU J.X., Li G., CHEN G.L., ZHAO H., QU J F. Changes of landscape ecological quality for land reclamation in mining area. Transactions of the Chinese Society of Agricultural Engineering. 29 (1):232, 2013 [in Chinese].

25. MORTBERG U.M., BALFORS B., KNOL W.C. Landscape ecological assessment: a tool for integrating biodiversity issues in strategic environmental assessment and planning. Journal of Environmental Management. 82, 457, 2007.

26. VAN L.D.W., CILLIERS S.S., KELLNER K., TONGWAY D.J., VAN R.L. Landscape functionality of plant communities in the Impala Platinum mining area, Rustenburg. Journal of Environmental Management. 113, 103, 2012.

27. ANDRE B.L., JACK A. Applying landscape ecological concepts and metrics in sustainable landscape planning. Landscape and Urban Planning. 59 (2), 65, 2002. 
28. ZHANG L.Q., WANG H.Z. Planning an ecological network of Xiamen Island (China) using landscape metrics and network analysis. Landscape and Urban Planning. 78, (4), 449, 2006.

29. ARTURO A.K., ERIC F., JESSICA F. Minimizing impacts of land use change on ecosystem services using multi-criteria heuristic analysis. Journal of Environmental Management. 156, 23, 2015.

30. MA F.Y. Research Advances on Ecosystem Stability. Journal of Desert Research. 22 (4), 4012002 [In Chinese].

31. RENATO F.V.J., SIMONE G.P.V., FERNANDO A.L.P., VITOR R.P., CATIA F.S., RUI M.V.C., LUIS F.S. Impacts of land use conflicts on riverine ecosystems. Land Use Policy. 43, 48, 2015.
32. RAFFAELLA F., BARBARA M., GIULIA C. A landscape analysis of land cover change in the Municipality of Rome (Italy): Spatial-temporal characteristics and ecological implications of land cover transitions from 1954 to 2001. Landscape and Urban Planning. 100 (1-2), 117, 2011.

33. KATERINA K., SILVIE S., MICHAELA M., JAN S. Landscape functions and their change - a review on methodological approaches. Ecological Engineering, 75, 378, 2015.

34. WANG Y.Q., BRAIN R.M., JARUNEE N.M., GREGORY B., ZHOU Y.Y., GREGORY S. Remote sensing of landcover change and landscape context of the National Parks: A case study of the Northeast Temperate Network. Remote Sensing of Environment. 113, 1453, 2009. 